OPEN ACCESS

Edited by:

Misty Good,

University of Pittsburgh School of Medicine and Children's Hospital of

Pittsburgh of UPMC, USA

Reviewed by:

Kimberly Jean Reidy, Children's Hospital at Montefiore and Albert Einstein College of Medicine,

USA

Jacqueline $\mathrm{Ho}$, Children's Hospital of Pittsburgh of UPMC, USA

*Correspondence: Andreas Kurtz andreas.kurtz@charite.de Kai M. Schmidt-Ott kai.schmidt-ott@charite.de

Specialty section

This article was submitted to Cell Growth and Division,

a section of the journal

Frontiers in Cell and Developmental

Biology

Received: 14 August 2015 Accepted: 23 October 2015 Published: 11 November 2015

Citation:

Hariharan K, Kurtz A and Schmidt-Ott KM (2015) Assembling Kidney Tissues from Cells: The Long

Road from Organoids to Organs.

Front. Cell Dev. Biol. 3:70.

doi: 10.3389/fcell.2015.00070

\section{Assembling Kidney Tissues from Cells: The Long Road from Organoids to Organs}

\author{
Krithika Hariharan ${ }^{1}$, Andreas Kurtz ${ }^{1,2 *}$ and Kai M. Schmidt-Ott ${ }^{1,3,4 *}$ \\ ${ }^{1}$ Berlin-Brandenburg Center for Regenerative Therapies, Charité-Universitätsmedizin Berlin, Berlin, Germany, ${ }^{2}$ College of \\ Veterinary Medicine, Seoul National University, Seoul, South Korea, ${ }^{3}$ Department of Nephrology, Charité- Universitätsmedizin, \\ Berlin, Germany, ${ }^{4}$ Max Delbrueck Center for Molecular Medicine in the Helmholtz Association, Berlin, Germany
}

The field of regenerative medicine has witnessed significant advances that can pave the way to creating de novo organs. Organoids of brain, heart, intestine, liver, lung and also kidney have been developed by directed differentiation of pluripotent stem cells. While the success in producing tissue-specific units and organoids has been remarkable, the maintenance of an aggregation of such units in vitro is still a major challenge. While cell cultures are maintained by diffusion of oxygen and nutrients, three- dimensional in vitro organoids are generally limited in lifespan, size, and maturation due to the lack of a vascular system. Several groups have attempted to improve vascularization of organoids. Upon transplantation into a host, ramification of blood supply of host origin was observed within these organoids. Moreover, sustained circulation allows cells of an in vitro established renal organoid to mature and gain functionality in terms of absorption, secretion and filtration. Thus, the coordination of tissue differentiation and vascularization within developing organoids is an impending necessity to ensure survival, maturation, and functionality in vitro and tissue integration in vivo. In this review, we inquire how the foundation of circulation is laid down during the course of organogenesis, with special focus on the kidney. We will discuss whether nature offers a clue to assist the generation of a nephro-vascular unit that can attain functionality even prior to receiving external blood supply from a host. We revisit the steps that have been taken to induce nephrons and provide vascularity in lab grown tissues. We also discuss the possibilities offered by advancements in the field of vascular biology and developmental nephrology in order to achieve the long-term goal of producing transplantable kidneys in vitro.

Keywords: pluripotent stem cells, organoids, stem cell differentiation, kidney development, vascularization

\section{INTRODUCTION}

While our knowledge on the structure and function of mature organs is mostly derived from animal models, human cadavers, or biopsies, the information we have on embryonic organ development is largely derived from various model organisms and from technologies that study human embryogenesis in vitro. In 1944, the first human egg was fertilized in vitro (Rock and Menkin, 1944). Edwards and Steptoe implanted a fertilized egg into a woman's uterus in 1977 (Steptoe and Edwards, 1978) giving the world its first test tube baby. These scientists were 
also paving the way for a closer observation of human embryonic development. Edwards and his team had worked on growing human embryos in vitro, until the blastocyst stage (Edwards et al., 1981) before re-implanting the embryo into the uterus. Knowing that in vitro culture was a suitable interim step in producing a viable organism spurred the goal of replacing damaged organs by transplanting organoids produced in vitro. Key advances in this field included the derivation of human embryonic stem cells (hESC) from the inner cell mass of normal human blastocysts (Thomson et al., 1998) and the generation of induced pluripotent stem cells (iPSC) (Takahashi and Yamanaka, 2006; Takahashi et al., 2007). These cells demonstrate evidence of stable developmental potential even after prolonged culture forming derivatives of all three embryonic germ layers from the progeny of a single cell. A huge advantage of iPSC over ESC, is the possibility to have pluripotent stem cells from every individual, providing an opportunity to study and repair genetic disorders at a personal level. Pluripotency has been exploited to recapitulate many embryonic processes in vitro, including primitive streak formation, neural tube induction, and trophoblast formation, extending to the generation of functioning neurons, beating cardio-myocytes, and insulin producing beta cells of the pancreas. Major achievements in the field of stem cell biology have been the derivation of a multitude of differentiated cell types morphologically similar to their terminally differentiated counterparts in vivo, but functionally immature in vitro, that have been intended to be used as regenerative cell sources in degenerative disease conditions. However, in order to model and study human disease, and to subsequently test and develop drugs, functionality of terminally differentiated cells has to be achieved.

Mammalian cells, as part of multicellular organisms, function in tissue units that contain several types of cells, which together form an organ. The fact that many ESC and iPSC-derived cell types display a mostly immature, fetal phenotype suggests that multicellularity is also a prerequisite for terminal differentiation. Nevertheless, the ability to derive specific cell types of any organ from PSCs has provided the possibility of constructing functional units of an organ, containing distinct cell types. Several groups pioneered the development of tissues in vitro from PSCs, including 3D cortical neuro-epithelium with up to 6 layers of neurons (Eiraku et al., 2008), intestinal (Spence et al., 2011), retinal, liver, inner ear, and kidney organoids (Eiraku et al., 2011; Nakano et al., 2012; Koehler et al., 2013; Takebe et al., 2013; Takasato et al., 2014) These novel findings prompted a redefinition of the term "organoid" as a collection of organspecific cell types that develop from stem cells or organ progenitors and self-organize through cell sorting and spatially restricted lineage commitment in a manner similar to the situation in vivo (Lancaster and Knoblich, 2014). Despite all the progress, no functional nephron or liver acini unit has been generated in vitro. In this review, we will revisit methods to differentiate tissue-specific cells from pluripotent stem cells, to achieve 3-dimensional tissue modeling, and discuss current efforts to enhance vascularization of organoids in vitro and in vivo.

\section{MIRRORING ORGANOGENESIS IN VITRO}

\section{Kidney-specific Cell Differentiation from Pluripotent Stem Cells}

Humans are triploblastic and thus, develop a tri-laminar embryo upon gastrulation, consisting of ectoderm, endoderm, and mesoderm. Several groups have cultured PSCs in a feeder free matrix-coated surface and promoted differentiation by adding growth factors and inhibitors to this 2D system, while other groups applied inductive media to a 3D system, after the generation of a sphere of PSC cells known as an embryoid body (EB). Protocols applying defined time periods and concentrations of exposure to inductive agents have allowed for the differentiation of endo-, ecto-, or mesodermal lineages and specific cell types. For example, activin signaling leads to $80 \%$ efficient induction of $\mathrm{SOX}_{1} 7^{+} / \mathrm{GSC}^{+} / \mathrm{FOXA}^{+} / \mathrm{MIXL}^{+}$ definitive endoderm in hESC cultures after 5 days of differentiation in $100 \mathrm{ng} / \mathrm{ml}$ activin A (D'Amour et al., 2005). In another seminal study, sequential treatment of high-density undifferentiated monolayer hESC cultures with activin A for $24 \mathrm{~h}$ and bone morphogenetic protein 4 (BMP4) for 4 days consistently yielded $>30 \%$ cardiomyocytes (Laflamme et al., 2007). For neural induction of hESCs, the growth factors insulin, epidermal growth factor (EGF) and basic fibroblast growth factor (bFGF) were added in a chemically defined medium giving rise to up to $90 \% \mathrm{PAX}^{+}$neural progenitors (Joannides et al., 2007). These studies have proved that while a spontaneously differentiating mass of PSC can generate varying proportions of endo- and ecto- and mesoderm, targeting signaling pathways prominent in the development of an organ of interest in a temporal fashion can promote that particular lineage. Over the years, researchers have tested various combinations of cell signaling modifiers to achieve enrichment of tissue-specific cell types in a heterogenous population of differentiated PSC progeny (reviewed by Murry and Keller, 2008). Moreover, the level of enrichment varies with the iPSC or ESC used. iPSC that are reprogrammed from a somatic cell type originating from an organ and are differentiated to a cell type of the same organ, show higher efficiencies owing to epigenetic memory of the source (Hiler et al., 2015). This highlights the need for standardization of protocols with certain PSC lines for certain lineages.

Unlike other organs, few protocols have been established for the kidney. The kidney exhibits a remarkable architectural complexity coupled with the presence of at least 26 different specialized cells (Al-Awqati and Oliver, 2002). The kidney is mesodermal in origin, arising from the intermediate mesoderm (IM). Arising from IM, the ureteric bud (UB) interacts with an adjacent cell population, the metanephric mesenchyme (MM). Through reciprocal interactions, the ureteric bud will generate the ureteric tree giving rise to the ureter, renal pelvis and collecting ducts, while progenitors within the metanephric mesenchyme will generate nephrons (Grobstein, 1953; Saxén and Sariola, 1987). Based on earlier studies that highlighted important molecules and pathways that drive mesodermal and nephron differentiation in model organisms, initial studies of differentiation toward the renal lineage were performed on mouse ESC EBs treated with media containing serum together 
with multiple combinations of factors including activin A, BMP4, BMP7, retinoic acid (RA), leukemia inhibiting factor (LIF), and glial-derived neurotrophic factor (GDNF) or UB-derived conditioned media. These protocols led to the generation of cells expressing markers of differentiation, e.g., Pax2 (kidney tubules), Aquaporin-2 (collecting duct principal cells), Wt1 (metanephric mesenchyme and podocytes), or Ksp-Cadherin (distal nephron tubules), within EBs, which provided evidence of successful renal lineage induction (Kobayashi et al., 2005; Bruce et al., 2007; Vigneau et al., 2007; Morizane et al., 2009; Ren et al., 2010; Nishikawa et al., 2012). Although a renal identity was achieved in the examples mentioned before, the desired cell types could not be isolated owing to low and varying frequencies of occurrence and their functionality was not demonstrated.

Meanwhile, genetic lineage tracing demonstrated that the induced Six2-expressing cap mesenchyme represents a nephron progenitor population that gives rise to all cell types of the nephron (Kobayashi et al., 2008). Also, the intermediate mesodermal origin of kidney cells was confirmed when Mugford et al., used molecular fate mapping to demonstrate that the majority of cell types within the metanephric kidney arise from an Osr1-expressing population within the intermediate mesoderm (Mugford et al., 2008). These new findings were considered in differentiation protocols to distinguish the exact mesodermal cell sub-type required to enrich cultures of PSC-derived renal progeny. For instance, Mae et al developed a robust protocol using activin A and Wnt-agonist CHIR99021 for 2 days and sequential treatment with BMP7 and CHIR99021 for 8 days to obtain 90\% OSR1 ${ }^{+}$cells (Mae et al., 2013). Despite such an efficient protocol, the dependence on OSR1 as a population identifier created ambiguity, since even though OSR 1 is expressed in the intermediate mesoderm, it is also expressed in the earlier mesoderm prior its subdivision into paraxial and intermediate domains (Guillaume et al., 2009). Moreover, OSR1 is expressed in both the intermediate mesoderm and lateral plate (James and Schultheiss, 2003; Wilm et al., 2004).

Additional protocols were developed to induce different cell types within the nephron. Human PSC derived podocytes expressing podocin, nephrin, and synaptopodin were generated from EBs using treatment with Activin A, RA, and BMP7 and plating on gelatin (Song et al., 2012). In another study, $\sim 30 \% \mathrm{AQP}^{+}$proximal tubule cells were obtained by treating a monolayer PSC culture with media containing RA, BMP2, and BMP7 for 20 days (Narayanan et al., 2013). Recent reports demonstrated stepwise induction of UB and/or MM through systematic induction of primitive streak alone, followed by intermediate mesodermal specification (Xia et al., 2013, 2014; Lam et al., 2014; Taguchi et al., 2014; Takasato et al., 2014). These studies performed thorough characterization of cell types obtained at every stage, focusing on obtaining $\mathrm{PAX}^{+}$ GATA3 $^{+}$LHX1 $^{+}$UB cells (Xia et al., 2013) and SIX2 ${ }^{+}$PAX2 $^{+}$ $\mathrm{OSR}^{+-}{ }^{+} \mathrm{GDNF}^{+} \mathrm{HOX}_{1}{ }^{+} \mathrm{WT}^{+} \mathrm{MM}$ cells (Taguchi et al., 2014). Takasato et al. were able to generate UB and MM between 14 and 18 days, whereas Lam et al generated SIX2 ${ }^{+}$SALL1 $^{+}$ $\mathrm{WT}^{+}$cap mesenchyme by 8 days and showed the potency of $\mathrm{PAX}_{2}{ }^{+} \mathrm{LHX}^{+}{ }^{+}$imtermediate mesodermal cells to generate tubule structures that express Lotus lectin and Ksp-Cadherin after 9 days of differentiation (Lam et al., 2014; Takasato et al., 2014).

Together, these important studies provided proof of principle that most if not all components of the kidney can be induced from PCS. The PSC-derived UB cells can be utilized to generate a ureteric tree or PSC-derived MM cells can be coaxed to produce S-shaped bodies that undergo proximal distal patterning initiating tubulogenesis, giving rise to fetal nephrons in culture. It would also be interesting to use cells derived from the Xia protocol to generate UB and Taguchi protocol to obtain MM and investigate if they interact in a similar manner as these cell types do in vivo. Since most kidney diseases involve the damage and loss of podocytes or hypertrophy of tubular epithelial cells, these cell types have a high priority of being derived. On the other hand, the big picture of nephron reconstruction requires other specialized cells including mesangial cells, glomerular endothelial cells, epithelial cells of the loop of Henle, principal cells and intercalated cells that have not yet been procured from PSCs. Induction of terminal differentiation, recapitulation of the architectural context and building of functional nephrons of the kidney are key challenges to be mastered.

\section{Morphogenesis and Patterning}

The development of an organism involves not only differentiation of cells, but also their morphogenesis and appropriate patterning to form the architectural context of tissues and organs (Gilbert, 2000). Essentially, cells need to communicate with each other and their microenvironment, by means of growth factors, morphogens, cell adhesion molecules, and mechanoreceptors. The elegant experiments of Holtfreter and Townes studying Xenopus embryo re-aggregation patterns and organization indicated that a whole system of attraction and repulsion phenomena operates between various cell types during development and that information on this system will yield valuable information concerning the segregation of tissues during organogenesis. Holtfreter used the term "tissue affinity" (Gewebeaffinität) to describe this force (Holtfreter, 1939, 1944; Townes and Holtfreter, 1955). Steinberg's differential adhesion hypothesis supported the ideas of Holtfreter with thermodynamic principles (Steinberg, 1970) providing a partial explanation of the self-organizing properties of tissues. Embryonic tissue re-aggregation and adult organ-derived cells have demonstrated this property, e.g., in liver, lung, eye, brain, and thyroid gland (Weiss and Taylor, 1960; Grover, 1961a,b; Ishii, 1966; Hilfer et al., 1968; Stefanelli et al., 1977). The observation of such tissue affinity and self-assembly among PSC-derived progeny flags the success of recapitulating natural embryological behavior in vitro.

Toward this extent, one of the first reports of such a phenomenon in mouse PSC-differentiated cells came from the Sasai lab. The appearance of multi-layered cortical neuroepithelium in serum-free embryoid body-like aggregates in suspension culture, showed a similar pattern as observed during development. This remarkable finding could also be reproduced in hESCs (Eiraku et al., 2008). Further examples of selforganizing tissue morphogenesis were the generation of optic cups from mouse ESCs (Eiraku et al., 2011) and of neural 
retina from human ESCs (Nakano et al., 2012). Lancaster et al., developed 3-dimensional self-organizing cerebral organoids from human ESCs, which develop distinct interconnected brain regions (Lancaster et al., 2013). Spence et al. developed self-organizing intestinal organoids from human ESCs, which recapitulated cell types and the stem cell compartment of the intestine (Spence et al., 2011).

Partial self-organization of mouse embryonic kidney cells upon their re-aggregation after dissociation was first achieved by Unbekandt and Davies (2010). The novelty of this system was the introduction of a ROCK inhibitor, which prevented the dissociation-induced apoptosis within single cell suspensions and facilitated a significant recovery of re-aggregated tissues. The Unbekant re-aggregation method has since then been used as a test system to check the capacity of cells (e.g., PSC-derived cells) to integrate into forming tubules or glomeruli of the mouse nephron. While this method proves the property of test cells to contribute to kidney formation, it cannot provide proof of self-organization of PSC-derived renal progenitors. To this end, cases of kidney organogenesis from PSC have been reported by Takasato et al., where 18 days of differentiation of PSC seeded initially on matrigel, develop an $\mathrm{ECAD}^{+}$ ureteric epithelium surrounded by clumps of $\mathrm{SIX}^{+} \mathrm{WT}^{+}$ $\mathrm{PAX}^{+}{ }^{+} \mathrm{MM}$ cells or $\mathrm{JAG}^{+}{ }^{+} \mathrm{CDH}^{+}$renal vesicles (Takasato et al., 2014). Lam et al. also observed appearance of tubulelike structures positive for Lotus lectin (a proximal tubule marker) from SIX2 + cap mesenchyme cell cultures, obtained on day 7 of their differentiation procedure, upon treatment with CHIR99021 (Lam et al., 2014). This was reminiscent of induced metanephric mesenchyme that responds to Wnt signals to undergo mesenchymal-epithelial transition and form renal vesicles in vivo (Park et al., 2007; Schmidt-Ott et al., 2007). Meanwhile, the group of Nishinakamura had also obtained evidence of a slightly different nature. They used PSC in the form of EBs for a differentiation protocol that took 8.5 days in mouse ESCs and 14 days in human iPSCs, resulting in $\mathrm{SIX}^{+}{ }^{+} \mathrm{WT}^{+}{ }^{+} \mathrm{SALL}^{+}{ }^{+} \mathrm{PAX}^{+}{ }^{+} \mathrm{MM}$ cells that could give rise to tubules and podocytes when induced by mouse embryonic spinal cord (Taguchi et al., 2014). These studies are evidence that a systematic mirroring of embryonic kidney development in PSC derivatives can lead to the formation of organo-typical structures, as summarized in Table 1. This brings us a step closer to develop nephrons in vitro, as these structures can be coaxed under concentration gradients of growth factors to boost tubulogeneis. Yet, there is clearly a need to enhance protocols to achieve full maturation of nephrons that have on one hand a filtering unit and on the other hand an optimal spatial orientation of tubules and trigger their functionality in terms of electrolyte transport.

A niche for organogenesis was created in post-blastocyst mutant mouse embryos that are genetically precluded from developing a particular organ by Kobayashi et al. The group generated a chimeric animal where injected PSC-derived cells colonized this developmental niche and compensated for the developmental defect to form a donor-induced organ in vivo. They injected rat wild-type PSCs into $P d x 1^{-/-}$mouse blastocysts, generating normally functioning rat pancreas in $P d x 1^{-/-}$mice. These data constituted proof of principle for interspecific blastocyst complementation and for generation of organs derived from donor PSCs using a xenogenic environment in vivo (Kobayashi et al., 2010). On similar lines, the same group injected mouse PSCs in Sall1-deficient mice, since Sall1 is expressed in the metanephric mesenchyme-derived structures in the developing kidney. The kidneys of Sall1 ${ }^{-/-}$chimeric mice were almost entirely composed of EGFP-marked mouse iPSCderived cells. These iPSC-derived kidneys of Sall1 ${ }^{-/-}$chimeric mice were grossly normal in shape and size. Bladders of these mice were filled with urine, indicating that the iPS-derived kidneys were functional and appropriately connected to the lower urinary tract (Usui et al., 2012). It can be anticipated that human organs can similarly be developed in animal hosts.

\section{REVISITING RENAL DEVELOPMENT-MATURATION OF NEPHRONS}

Kidney organoids obtained in vitro are comparable to E12.5E13.5 metanephric mouse kidneys, where in, the ureteric tree

TABLE 1 | Status of lab-grown kidney organoids.

\begin{tabular}{|c|c|c|}
\hline Cell source & Description & References \\
\hline \multicolumn{3}{|l|}{ IN VITRO } \\
\hline \multirow[t]{2}{*}{ Embryonic cells } & Suspension culture of dissociated-reaggregated chick mesonephric cells & Moscona and Moscona, 1952 \\
\hline & Culture at air-medium interface of dissociated- reaggregated mouse metanephric cells & Unbekandt and Davies, 2010 \\
\hline Adult cells & Collagen matrix embedded murine and human renal cells & Joraku et al., 2009; Guimaraes-Souza et al., 2012 \\
\hline \multirow[t]{2}{*}{ PSC- derived cells } & 2-dimensional culture of 18 day differentiated hPSC & Takasato et al., 2014 \\
\hline & 14-day differentiated EBs induced with mouse embryonic spinal cord & Taguchi et al., 2014 \\
\hline \multicolumn{3}{|l|}{ IN VIVO } \\
\hline \multirow[t]{3}{*}{ Embyonic cells } & Mouse metanephric cells cultured on CAM of avian embryos & Preminger et al., 1980 \\
\hline & Rat metanephroic cells transplanted in the omentum of a rat & Hammerman, 2002 \\
\hline & Mouse metanephric cells cultivated in mouse lymph node & Francipane and Lagasse, 2015 \\
\hline \multirow[t]{2}{*}{ PSC-derived cells } & Mouse embryonic spinal cord-induced EBs transplanted under the kidney capsule of mice & Taguchi et al., 2014 \\
\hline & Sall1- deficient mouse blastocyst, complemented with wildtype mouse PSCs & Usui et al., 2012 \\
\hline
\end{tabular}


has branched and the cap mesenchyme undergoes mesenchymalto-epithelial transition into renal vesicles, which elongate and undergo patterning to form comma-shaped and S-shaped bodies that are scattered in the cortex. In parallel, the renal stroma, derived from Foxd1 ${ }^{+}$cells and $\mathrm{Flk}^{+}$cell derived vasculature, are also contributing to development of kidney architecture (Hatini et al., 1996; Robert et al., 1996; Abrahamson et al., 1998). Formation of renal vasculature is a combination of angiogenesis and vasculogenesis. The lateral branch of the aorta invades the kidney at E12.5 and becomes the renal artery that has 3-4 branches by E13.5. Around E17.5, the arterial tree extends until the cortex due to strong VEGFA signals from developing podocytes in the glomerular zone, leading to the formation of afferent arterioles. Although it has been observed that at around E13-14, endothelial cells migrate into the cleft of glomeruli to form a capillary network, the source of these cells remains elusive (Herzlinger and Hurtado, 2014). Lineage tracing of Tie1/LacZ E11 metanephroi transplanted into a nephrogenic cortex has shown that endothelial precursors exist before the onset of nephrogenesis since the donor tissue showed transgene-expression in glomerular capillary loops (Loughna et al., 1997). A cKIT ${ }^{+}$cell population originating from the aortagonad-mesonephros hemangioblasts has also been observed during E10.5-E11.5 that are distinct from Foxd1+ stromal cells (Schmidt-Ott et al., 2006), the fate of these cells has not been examined. Foxd1+ stromal derivatives differentiate into peritubular capillary endothelial cells that can be observed around E18.5 (Sims-Lucas et al., 2013) and also secrete factors required for normal nephron and vascular differentiation (Das et al., 2013; Hum et al., 2014).

Rymer et al. performed in utero embryonic intra-cardiac injection of tomato lectin (TL) to label perfused blood vessels at different stages of development (E11.5-E17). They found that perfused blood vessels were closely linked to mature nephron structures, while the nephrogenic zone did not show evidence of blood flow. This suggests that terminal differentiation is linked to an oxygen-rich environment, while multipotent nephron progenitors exist under low oxygen conditions (Rymer et al., 2014). This finding is potentially important with respect to tissue engineering, since strategies to establish blood flow and oxygenation within organoids may provide a critical step toward generating mature renal tissues.

\section{BRINGING BLOOD INTO AN ORGANOID-VASCULARIZATION STRATEGIES}

PSC-derived tissue specific cell types irrespective of being generated in a 2- or 3-dimensional culture are functionally immature despite having morphological properties of the desired cell type. Essential functions of the kidney, including glomerular filtration, tubular reabsorption, or hormone secretion, essentially dependent on the presence of a vasculature. In addition, the diffusion limit of oxygen in organ cultures is around $150 \mu \mathrm{m}$, while the organoids that are currently being developed range from 1 to $2 \mathrm{~mm}$, raising an issue of oxygen deprivation in the core regions gradually leading to tissue decay.

Learning from embryonic vascular development, each organ has progenitors distributed in the primordia that develop into the vasculature of the respective organ. Growth factors acting on these progenitors, including VEGF (Tufro et al., 1999), stem cell factor (SCF) (Schmidt-Ott et al., 2006), and Ang1 (Loughna et al., 1997; Woolf et al., 2009) can be supplemented into culture media to enrich the differentiated progeny. Xinaris et al. used 5-day-organoids derived from E11.5 mouse kidney, dissociated into single cells, and used a protocol involving VEGF treatment and transplantation of these cells under the kidney capsule of athymic rats. This facilitated vascularization with blood vessels from donor (mouse) origin, in vivo viability for at least 3 weeks, and glomerular maturation characterized by formation of capillary walls with fenestrated endothelium, podocytes with foot processes and slit diaphragms. Moreover, FITC-conjugated albumin injections were recovered in proximal tubules suggesting successful glomerular filtration and tubular reabsorption in these allografts (Xinaris et al., 2012).

Another approach that could enhance vascularization of organoids that are considerably thick is in vitro addition of vascular and perivascular cells. Formation of micro-capillary like structures by endothelial cells prior to transplantation accelerates anastomosis with host vasculature. The first report of in vitro prevascularized tissues was the generation of a skin equivalent by culturing dermal fibroblasts, keratinocytes and human umblical veil endothelial cells (HUVECs) (Black et al., 1998; Tonello et al., 2003). Stevens et al constructed "tri-cell" cardiac patches containing hESC-derived cardiomyocytes, HUVECs, and mouse embryonic fibroblasts (MEFs) in 1:1:0.5 ratios, respectively (cardio-HUVEC-MEF patches). In sharp contrast to cardioHUVEC patches, addition of MEFs to human cardiomyocytes and HUVECs resulted in the formation of human CD31-positive endothelial cell networks that morphologically resembled a vascular plexus (Stevens et al., 2009). Similar success has been reported in generating a human liver bud where PSC-derived hepatic progenitors, human mesenchymal stromal cells(hMSC) and HUVECs were co-cultured in vitro prior to cranial transplantation in immune-deficient mice (Takebe et al., 2013). As a development to the previous study, Takebe et al. also developed kidney buds by substituting PSC-derived hepatic progenitors with E13.5 kidney derived dissociated cells that could form glomerular like micro-tissues after 8 days of transplantation followed by quick vascularization (Takebe et al., 2015).

A step closer toward a vascularized organoid is the use of scaffolds that are pre-vascularized with HUVECs with or without perivascular cells, followed by seeding of dissociated cells of the organoid or just PSC-derived sorted progenitors. Acellular porcine or rodent kidney matrices have been repopulated with HUVECs lining vessel walls and fetal kidney cells in tubular and glomerular compartments; orthotopic transplantation of the reseeded kidney in single nephrectomized rats showing blood flow through the vasculature and urine production (Song et al., 2013). Miller et al. printed rigid 3D filament networks of carbohydrate glass in the engineered tissue to generate cylindrical networks that can be lined by endothelial cells and perfused, 
offers an independent extravascular tissue. Initially, a mixture of glucose, sucrose, and dextran was developed such that it formed a glass when cooled and optically transparent such that it could be used in conjunction with photo-cross-linkable materials. The carbohydrate glass was then extruded through a heated syringe into an interconnected microfluidic vascular network allowed to cool, and a scaffold was cast around it in a mixture of mouse fibroblast cells and photo-cross-linkable ECM pre-polymer. When immersed in water, the carbohydrate quickly dissolved, leaving a hollow network in its place (Miller et al., 2012). Bio-printing and micro-fabrication of cells embedded in hydrogel in a pattern generated from knowledge of renal architecture is an emerging technology that is still in its infancy. Currently, acellular adult kidneys and bio-printing are methods that may provide architectural features similar to that of an adult organ, and hold a promising future for creating vascularized transplantable organs in vitro. Current limitations of bioprinting are dimensional, with minimal sizes approaching 30-50 $\mu \mathrm{m}$, and the availability of adequate materials. Extracellular matrix printing seems to provide some benefit over other polymers in terms of cell survival and differentiation. Its combination with shape controllable polymers, for example to print preformed scaffolds that are then filled with matrix containing cells or cell clusters will perhaps lead to readily generated 3-dimensional and properly tubulized tissues. What remains to be figured out is which cell type can be chosen to repopulate such a prevascularized-scaffold. Among various other candidates, would several PSC-derived organoids occupy the matrix and develop a nephron-vascular system or is it sufficient to use a cocktail of PSC-derived terminal cell types and allow them to anchor to the scaffold and attain function?

The simplest method to vascularize the kidney organoid would involve connection to an extrinsic vascular supply. This was first demonstrated by Sariola et al., when they grafted mouse embryonic kidney explants on to chorio-allantoic-membrane (CAM) of a quail and maintained them for 5-10 days. The grafted kidney gave rise to well- developed convoluted secretory tubules and highly branched collecting ducts. Definitive glomeruli were also identified in these grafts by the presence of efferent tubules, visceral and parietal epithelium, capillary tuft, and Bowman's space. These CAM grafts appeared histologically comparable to the 14- 15 -day in vivo embryonic metanephros (Preminger et al., 1980). Following this example, Taguchi et al placed mouse-PSCderived MM cell mass induced by mouse spinal cord beneath the kidney capsule of immunodeficient mice. When harvested after a week, tubulogenesis and glomerular formation was seen as expected and around $84.6 \%$ of the glomeruli showed integration of vessels from the host. This demonstrates maturation of the induced EB in presence of a vascular supply (Taguchi et al., 2014).

Ectopic organogenesis has been extended to several sites in vivo, since the kidney capsule restricts space availability for the maturating renal primordia. Transplantation of E15 rat metanephroi into omentum of non-immunosuppressed adult rats resulted in a normal kidney structure and function following uretero-uterostomy, surviving as long as 32 weeks (Hammerman, 2002). A recent study by the Lagasse group has reported the successful organogenesis of the kidney using the mouse lymph node as a developmental niche. Some of their findings include the survival of neo-kidneys until the 12th week of transplantation, engraftment and maturation of metanephroi although fluid waste accumulation resulted in graft degeneration. Moreover, nephrectomy of the mice resulted in accelerated organogenesis suggesting a compensatory response (Francipane and Lagasse, 2015). To determine whether the fetal kidney could provide a suitable niche for MSCs to generate renal tissue, Yokote and Yokoo (2013) injected GDNF-expressing human MSCs into rodent whole-embryo cultures at the point of budding. MSC were shown to integrate into the developing fetal kidney forming a chimeric organ leading to a possibility that depletion of animal cells in this chimeric kidney after transplantation into the omentum of human patients would allow further development of the kidney only from human cells (Yokoo and Kawamura, 2009; Yokote and Yokoo, 2013). The result that we aim for in any case, is a kidney that when perfused with blood/ equivalent of body fluids can filter larger proteins and reabsorb electrolytes to secrete a urine concentrate into a functional ureter. Further molecular and cellular investigations of the afore-mentioned experiments of in vivo vascularization of kidney organoids (listed in Table 2)

TABLE 2 | Strategies to develop a nephro-vascular unit.

\begin{tabular}{|c|c|c|}
\hline Strategy & Description & References \\
\hline Growth factor induction & VEGF, SCF, Ang-1 & $\begin{array}{l}\text { Loughna et al., 1997; Tufro et al., 1999; } \\
\text { Schmidt-Ott et al., 2006; Woolf et al., } 2009\end{array}$ \\
\hline \multirow[t]{2}{*}{ Co-culture with peri-vascular cell types } & Fibroblasts and endothelial cells & Black et al., 1998; Tonello et al., 2003 \\
\hline & Mesenchymal stromal cells and endothelial cells & Takebe et al., 2013, 2015 \\
\hline Providing architectural and mechanical support & $\begin{array}{l}\text { Endothelialization followed by repopulation with kidney cells of } \\
\text { - an acellular organ matrix } \\
\text { - 3D printed polymer-based network } \\
\text { Suitable for perfusion through endothelial channels }\end{array}$ & $\begin{array}{l}\text { Nakayama et al., 2010; Miller et al., 2012; Song } \\
\text { et al., } 2013\end{array}$ \\
\hline
\end{tabular}

CAM

Beneath the kidney capsule of a rodent

Omentum of a rodent

Rodent lymph node
Preminger et al., 1980

Taguchi et al., 2014

Hammerman, 2002

Francipane and Lagasse, 2015 
can provide valuable lessons on how the vascular networks are established and can be transferred to in vitro experiments conducted on scaffolds, increasing our chances to develop a nephron-vascular unit.

\section{OUTLOOK}

The options for generating vascularized tissues suitable for in vitro assays or for regenerative medicine have increased greatly in the last decade. Vascularization is achievable in vitro by means of preformed natural or artificial printed or casted scaffolds or pre-established endothelialized networks, which can then be populated with tissue cells, depending on the application. The populating cells may lead to further remodeling and capillary formation, which could be directed using switchable expression of angiogenic factors. Alternatively, supplying tissues, cells or organoids undergoing morphogenesis with vascular or lymphatic precursor cells may be useful to enable the tissue to autonomously generate vascularity or to allow faster vascularization post transplantation. The perfusion of the vascular system in vitro will become feasible with advanced microfluidics devices and bioreactors for larger organs.

In addition, vascularization of preformed avascular organoids is achievable in vivo, by transplantation either ectopically or at the organ specific target site. The aggregation of pre-formed smaller functional tissue units or organoids may be a technique to build larger organs. These smaller units could be either avascular or preconditioned with endothelial cells or suitable scaffolds to quickly vascularize the larger aggregates. The provision of larger vessel adapters to allow direct connectivity to the host's vascular net will provide blood supply early after transplantation. Finally, the generation of embryonic or adult human organs in vivo would allow complete vascularization after transplantation to environmental niches that permit continuing organogenesis. These niches could be provided in vitro and in vivo. Based on this approach, growth of pre-vascular fetal human kidneys in transgenic kidney deficient mice may be used to generate kidney primordia for transplantation and vascularization in adult

\section{REFERENCES}

Abrahamson, D. R., Robert, B., Hyink, D. P., St John, P. L., and Daniel, T. O. (1998). Origins and formation of microvasculature in the developing kidney. Kid. Intern. 54, S7-S11. doi: 10.1046/j.1523-1755.1998.06702.x

Al-Awqati, Q., and Oliver, J. A. (2002). Stem cells in the kidney. Kidn. Intern. 61, 387-395. doi: 10.1046/j.1523-1755.2002.00164.x

Black, A. F., Berthod, F., L'heureux, N., Germain, L., and Auger, F. A. (1998). In vitro reconstruction of a human capillary-like network in a tissue-engineered skin equivalent. FASEB J. 12, 1331-1340.

Bruce, S. J., Rea, R. W., Steptoe, A. L., Busslinger, M., Bertram, J. F., and Perkins, A. C. (2007). In vitro differentiation of murine embryonic stem cells toward a renal lineage. Differentiation 75, 337-349. doi: 10.1111/j.1432-0436.2006.00149.x

D’Amour, K. A., Agulnick, A. D., Eliazer, S., Kelly, O. G., Kroon, E., and Baetge, E. E. (2005). Efficient differentiation of human embryonic stem cells to definitive endoderm. Nat. Biotechnol. 23, 1534-1541. doi: 10.1038/nbt1163

Das, A., Tanigawa, S., Karner, C. M., Xin, M., Lum, L., Chen, C., et al. (2013). Stromal-epithelial crosstalk regulates kidney progenitor cell differentiation. Nat. Cell Biol. 15, 1035-1044. doi: 10.1038/ncb2828 human hosts. The establishment of a fully humanized kidney in vivo, including human derived vasculature and innervation may also be achieved using hMSC in an animal model as demonstrated by Yokote et al. (2015). Similarly, adult kidneys could be generated in donor animals that promote development of fully humanized organs and transplanted or used in perfusion systems.

Striking advances have also been achieved regarding the toolbox for generating human cells that are useful to generate tissue specific organoids. This includes the establishment of well characterized adult and fetal tissue derived primary differentiated and precursor cells, as well as of PSC-derived endothelial, lymphangiogenic, and organ specific cells. Endothelial cells and vasculatures have tissue-specific characteristics, for example in the kidney glomerulus they are highly fenestrated and differentiate in close association with podocytes. Whether iPSCderived endothelial cells are able to acquire the tissue specific phenotype needs to be investigated. The design of cells with tailored function is another option where the basic technologies are already known. It can be expected that design of cells will advance to the tissue and organoid level including cells with vascularizing functions.

Applications of organoids, which model function and structure of the kidney, are not restricted to understanding human kidney development. They are applicable to study the pathogenesis of genetic diseases as patient -derived PSC can be used for organoid generation. These are equally applicable for drug testing as PSC can be stratified according to patient cohorts and organoids functionally characterized in vitro as well as in vivo post grafting. Finally, organoids may be applicable in regenerative medicine to replace or repair functional tissue units.

\section{ACKNOWLEDGMENTS}

This work was funded by the German Research Foundation [Emmy-Noether grant (to KS), Research Unit 667 grant (to KS), and Research Unit 1368 grant (to KS)] and the Urological Research Foundation.

Edwards, R. G., Purdy, J. M., Steptoe, P. C., and Walters, D. E. (1981). The growth of human preimplantation embryos in vitro. Am. J. Obstetr. Gynecol. 141, 408-416.

Eiraku, M., Takata, N., Ishibashi, H., Kawada, M., Sakakura, E., Okuda, S., et al. (2011). Self-organizing optic-cup morphogenesis in three-dimensional culture. Nature 472, 51-56. doi: 10.1038/nature09941

Eiraku, M., Watanabe, K., Matsuo-Takasaki, M., Kawada, M., Yonemura, S., Matsumura, M., et al. (2008). Self-organized formation of polarized cortical tissues from ESCs and its active manipulation by extrinsic signals. Cell Stem Cell 3, 519-532. doi: 10.1016/j.stem.2008. 09.002

Francipane, M. G., and Lagasse, E. (2015). The lymph node as a new site for kidney organogenesis. Stem Cells Transl. Med. 4, 295-307. doi: 10.5966/sctm.20140208

Gilbert, S. F. (2000). Developmental Biology, 6th Edn. Sunderland, MA: Sinauer Associates.

Grobstein, C. (1953). Inductive epitheliomesenchymal interaction in cultured organ rudiments of the mouse. Science N.Y. 118, 52-55. doi: $10.1126 /$ science. 118.3054 .52 
Grover, J. W. (1961a). The enzymatic dissociation and reproducible reaggregation in vitro of 11-day embryonic chick lung. Dev. Biol. 3, 555-568. doi: 10.1016/0012-1606(61)90032-X

Grover, J. W. (1961b). The relation between the embryonic age of dissociated chick lung cells and their capacity for reaggregation and histogenesis in vitro. Exp. Cell Res. 24, 171-173. doi: 10.1016/0014-4827(61) 90266-X

Guillaume, R., Bressan, M., and Herzlinger, D. (2009). Paraxial mesoderm contributes stromal cells to the developing kidney. Dev. Biol. 329, 169-175. doi: 10.1016/j.ydbio.2009.02.034

Guimaraes-Souza, N. K., Yamaleyeva, L. M., AbouShwareb, T., Atala, A., and Yoo, J. J. (2012). In vitro reconstitution of human kidney structures for renal cell therapy. Nephrol. Dialys. Transplant. 27, 3082-3090. doi: 10.1093/ ndt/gfr785

Hammerman, M. R. (2002). Transplantation of developing kidneys. Transplant. Rev. 16, 62-71. doi: 10.1053/trre.2002.29160

Hatini, V., Huh, S. O., Herzlinger, D., Soares, V. C., and Lai, E. (1996). Essential role of stromal mesenchyme in kidney morphogenesis revealed by targeted disruption of winged helix transcription factor BF-2. Genes Dev. 10, 1467-1478. doi: 10.1101/gad.10.12.1467

Herzlinger, D., and Hurtado, R. (2014). Patterning the renal vascular bed. Sem. Cell Dev. Biol. 36, 50-56. doi: 10.1016/j.semcdb.2014.08.002

Hiler, D., Chen, X., Hazen, J., Kupriyanov, S., Carroll, P. A., Qu, C., et al. (2015). Quantification of retinogenesis in 3D cultures reveals epigenetic memory and higher efficiency in iPSCs derived from rod photoreceptors. Cell Stem Cell 17, 101-115. doi: 10.1016/j.stem.2015.05.015

Hilfer, S. R., Iszard, L. B., and Hilfer, E. K. (1968). Follicle formation in the embryonic chick thyroid. II. Reorganization after dissociation. Zeitschr. Zellforsch. Mikroskopis. Anat. 92, 256-69.

Holtfreter, J. (1939). Gewebsaffinität, Ein Mittel Der Embryonalen Formbildung. Available online at: http://repositorio.fciencias.unam.mx:8080/xmlui/handle/ $11154 / 171815$

Holtfreter, J. (1944). A study of the mechanics of gastrulation. J. Exp. Zool. 95, 171-212. doi: 10.1002/jez.1400950203

Hum, S., Rymer, C., Schaefer, C., Bushnell, D., and Sims-Lucas, S. (2014). Ablation of the renal stroma defines its critical role in nephron progenitor and vasculature patterning. PLoS ONE 9:e88400. doi: 10.1371/journal.pone.0088400

Ishii, K. (1966). Reconstruction of dissociated chick brain cells in rotationmediated culture. Cytologia 31, 89-98. doi: 10.1508/cytologia.31.89

James, R. G., and Schultheiss, T. M. (2003). Patterning of the avian intermediate mesoderm by lateral plate and axial tissues. Dev. Biol. 253, 109-124. doi: 10.1006/dbio.2002.0863

Joannides, A. J., Fiore-Hériché, C., Battersby, A. A., Athauda-Arachchi, P., Bouhon, I. A., Williams, L., et al. (2007). A scaleable and defined system for generating neural stem cells from human embryonic stem cells. Stem Cells 25, 731-737. doi: 10.1634/stemcells.2006-0562

Joraku, A., Stern, K. A., Atala, A., and Yoo, J. J. (2009). In vitro generation of three-dimensional renal structures. Methods 47, 129-133. doi: 10.1016/j.ymeth.2008.09.005

Kobayashi, A., Valerius, M. T., Mugford, J. W., Carroll, T. J., Self, M., Oliver, G., et al. (2008). Six 2 defines and regulates a multipotent self-renewing nephron progenitor population throughout mammalian kidney development. Cell Stem Cell 3, 169-181. doi: 10.1016/j.stem.2008.05.020

Kobayashi, T., Tanaka, H., Kuwana, H., Inoshita, S., Teraoka, H., Sasaki, S., et al. (2005). Wnt4-transformed mouse embryonic stem cells differentiate into renal tubular cells. Biochem. Biophys. Res. Commun. 336, 585-595. doi: 10.1016/j.bbrc.2005.08.136

Kobayashi, T., Yamaguchi, T., Hamanaka, S., Kato-Itoh, M., Yamazaki, Y., Ibata, M., et al. (2010). Generation of rat pancreas in mouse by interspecific blastocyst injection of pluripotent stem cells. Cell 142, 787-799. doi: 10.1016/j.cell.2010.07.039

Koehler, K. R., Mikosz, A. M., Molosh, A. I., Patel, D., and Hashino, E. (2013). Generation of inner ear sensory epithelia from pluripotent stem cells in 3D culture. Nature 500, 217-221. doi: 10.1038/nature12298

Laflamme, M. A., Chen, K. Y., Naumova, A. V., Muskheli, V., Fugate, J. A., Dupras, S. K., et al. (2007). Cardiomyocytes derived from human embryonic stem cells in pro-survival factors enhance function of infarcted rat hearts. Nat. Biotechnol. 25, 1015-1024. doi: 10.1038/nbt1327
Lam, A. Q., Freedman, B. S., Morizane, R., Lerou, P. H., Valerius, M. T., and Bonventre, J. V. (2014). Rapid and efficient differentiation of human pluripotent stem cells into intermediate mesoderm that forms tubules expressing kidney proximal tubular markers. J. Am. Soc. Nephrol. 25, 1211-1225. doi: 10.1681/ASN.2013080831

Lancaster, M. A., and Knoblich, J. A. (2014). Organogenesis in a dish: modeling development and disease using organoid technologies. Science N.Y. 345:1247125. doi: $10.1126 /$ science. 1247125

Lancaster, M. A., Renner, M., Martin, C.-A., Wenzel, D., Bicknell, L. S., Hurles, M. E., et al. (2013). Cerebral organoids model human brain development and microcephaly. Nature 501, 373-379. doi: 10.1038/nature12517

Loughna, S., Hardman, P., Landels, E., Jussila, L., Alitalo, K., and Woolf, A. S. (1997). A molecular and genetic analysis of renalglomerular capillary development. Angiogenesis 1, 84-101. doi: 10.1023/A:1018357116559

Mae, S.-I., Shono, A., Shiota, F., Yasuno, T., Kajiwara, M., Gotoda-Nishimura, N., et al. (2013). Monitoring and robust induction of nephrogenic intermediate mesoderm from human pluripotent stem cells. Nat. Commun. 4, 1367. doi: $10.1038 /$ ncomms 2378

Miller, J. S., Stevens, K. R., Yang, M. T., Baker, B. M., Nguyen, D.-H. T., Cohen, D. M., et al. (2012). Rapid casting of patterned vascular networks for perfusable engineered three-dimensional tissues. Nat. Mat. 11, 768-774. doi: $10.1038 /$ nmat3357

Morizane, R., Monkawa, T., and Itoh, H. (2009). Differentiation of murine embryonic stem and induced pluripotent stem cells to renal lineage in vitro. Biochem. Biophys. Res. Commun. 390, 1334-1339. doi: 10.1016/j.bbrc.2009.10.148

Moscona, A., and Moscona, H. (1952). The dissociation and aggregation of cells from organ rudiments of the early chick embryo. J. Anat. 86, 287-301.

Mugford, J. W., Sipilä, P., McMahon, J. A., and McMahon, A. P. (2008). Osr1 expression demarcates a multi-potent population of intermediate mesoderm that undergoes progressive restriction to an Osr1-dependent nephron progenitor compartment within the mammalian kidney. Dev. Biol. 324, 88-98. doi: 10.1016/j.ydbio.2008.09.010

Murry, C. E., and Keller, G. (2008). Differentiation of embryonic stem cells to clinically relevant populations: lessons from embryonic development. Cell 132, 661-680. doi: 10.1016/j.cell.2008.02.008

Nakano, T., Ando, S., Takata, N., Kawada, M., Muguruma, K., Sekiguchi, K., et al. (2012). Self-formation of optic cups and storable stratified neural retina from human ESCs. Cell Stem Cell 10, 771-785. doi: 10.1016/j.stem.2012.05.009

Nakayama, K. H., Batchelder, C. A., Lee, C. I., and Tarantal, A. F. (2010). Decellularized rhesus monkey kidney as a three-dimensional scaffold for renal tissue engineering. Tiss. Eng. Part A 16, 2207-2216. doi: 10.1089/ten.tea.2009.0602

Narayanan, K., Schumacher, K. M., Tasnim, F., Kandasamy, K., Schumacher, A., Ni, M., et al. (2013). Human embryonic stem cells differentiate into functional renal proximal tubular-like cells. Kid. Intern. 83, 593-603. doi: 10.1038/ki.2012.442

Nishikawa, M., Yanagawa, N., Kojima, N., Yuri, S., Hauser, P. V., Jo, O. D., et al. (2012). Stepwise renal lineage differentiation of mouse embryonic stem cells tracing in vivo development. Biochem. Biophys. Res. Commun. 417, 897-902. doi: 10.1016/j.bbrc.2011.12.071

Park, J.-S., Valerius, M. T., and McMahon, A. P. (2007). Wnt/beta-catenin signaling regulates nephron induction during mouse kidney development. Development 134, 2533-2539. doi: 10.1242/dev.006155

Preminger, G. M., Koch, W. E., Fried, F. A., and Mandell, J. (1980). Utilization of the chick chorioallantoic membrane for in vitro growth of the embryonic murine kidney. Am. J. Anat. 159, 17-24. doi: 10.1002/aja.1001590103

Ren, X., Zhang, J., Gong, X., Niu, X., Zhang, X., Chen, P., et al. (2010). Differentiation of murine embryonic stem cells toward renal lineages by conditioned medium from ureteric bud cells in vitro. Acta Biochim. Biophys. Sin. 42, 464-471. doi: 10.1093/abbs/gmq046

Robert, B., St John, P. L., Hyink, D. P., and Abrahamson, D. R. (1996). Evidence that embryonic kidney cells expressing Flk-1 are intrinsic, vasculogenic angioblasts. Am. J. Physiol. 271(3 Pt 2), F744-F753.

Rock, J., and Menkin, M. F. (1944). In vitro fertilization and cleavage of human ovarian eggs. Science 100, 105-107. doi: 10.1126/science.100.2588.105

Rymer, C., Paredes, J., Halt, K., Schaefer, C., Wiersch, J., Zhang, G., et al. (2014). Renal blood flow and oxygenation drive nephron progenitor differentiation. Am. J. Physiol. Ren. Physiol. 307, F337-F345. doi: 10.1152/ajprenal.00208.2014 
Saxén, L., and Sariola, H. (1987). Early organogenesis of the kidney. Pediatric Nephrol. 1, 385-392. doi: 10.1017/CBO9780511565083

Schmidt-Ott, K. M., Chen, X., Paragas, N., Levinson, R. S., Mendelsohn, C. L., and Barasch, J. (2006). C-kit delineates a distinct domain of progenitors in the developing kidney. Dev. Biol. 299, 238-249. doi: 10.1016/j.ydbio.2006. 07.026

Schmidt-Ott, K. M., Masckauchan, T. N. H., Chen, X., Hirsh, B. J., Sarkar, A., Yang, J., et al. (2007). Beta-catenin/TCF/Lef controls a differentiation-associated transcriptional program in renal epithelial progenitors. Development 134, 3177-3190. doi: 10.1242/dev.006544

Sims-Lucas, S., Schaefer, C., Bushnell, D., Ho, J., Logar, A., Prochownik, E., et al. (2013). Endothelial progenitors exist within the kidney and lung mesenchyme. PLoS ONE 8:e65993. doi: 10.1371/journal.pone.0065993

Song, B., Smink, A. M., Jones, C. V., Callaghan, J. M., Firth, S. D., Bernard, C. A., et al. (2012). The directed differentiation of human iPS cells into kidney podocytes. PLoS ONE 7:e46453. doi: 10.1371/journal.pone.0046453

Song, J. J., Guyette, J. P., Gilpin, S. E., Gonzalez, G., Vacanti, J. P., and Ott, H. C. (2013). Regeneration and experimental orthotopic transplantation of a bioengineered kidney. Nat. Med. 19, 646-651. doi: 10.1038/nm.3154

Spence, J. R., Mayhew, C. N., Rankin, S. A., Kuhar, M. F., Vallance, J. E., Tolle, K., et al. (2011). Directed differentiation of human pluripotent stem cells into intestinal tissue in vitro. Nature 470, 105-109. doi: 10.1038/ nature09691

Stefanelli, A., Cataldi, E., and Ieradi, L. A. (1977). Specific synaptic systems in reaggregated spherules from dissociated chick cerebellum cultivated in vitro. Cell Tiss. Res. 182, 311-325. doi: 10.1007/BF00219767

Steinberg, M. S. (1970). Does differential adhesion govern self-assembly processes in histogenesis? equilibrium configurations and the emergence of a hierarchy among populations of embryonic cells. J. Exp. Zool. 173, 395-433. doi: $10.1002 /$ jez. 1401730406

Steptoe, P. C., and Edwards, R. G. (1978). Birth after the reimplantation of a human embryo. Lancet 2, 366. doi: 10.1016/S0140-6736(78)92957-4

Stevens, K. R., Kreutziger, K. L., Dupras, S. K., Korte, F. S., Regnier, M., Muskheli, V., et al. (2009). Physiological function and transplantation of scaffold-free and vascularized human cardiac muscle tissue. Proc. Natl. Acad. Sci. U.S.A. 106, 16568-16573. doi: 10.1073/pnas.0908381106

Taguchi, A., Kaku, Y., Ohmori, T., Sharmin, S., Ogawa, M., Sasaki, H., et al. (2014). Redefining the in vivo origin of metanephric nephron progenitors enables generation of complex kidney structures from pluripotent stem cells. Cell Stem Cell 14, 53-67. doi: 10.1016/j.stem.2013.11.010

Takahashi, K., Tanabe, K., Ohnuki, M., Narita, M., Ichisaka, T., Tomoda, K., et al. (2007). Induction of pluripotent stem cells from adult human fibroblasts by defined factors. Cell 131, 861-872. doi: 10.1016/j.cell.2007.11.019

Takahashi, K., and Yamanaka, S. (2006). Induction of pluripotent stem cells from mouse embryonic and adult fibroblast cultures by defined factors. Cell 126, 663-676. doi: 10.1016/j.cell.2006.07.024

Takasato, M., Er, P. X., Becroft, M., Vanslambrouck, J. M., Stanley, E. G., Elefanty, A. G., et al. (2014). Directing human embryonic stem cell differentiation towards a renal lineage generates a self-organizing kidney. Nat. Cell Biol. 16, 118-126. doi: 10.1038/ncb2894

Takebe, T., Enomura, M., Yoshizawa, E., Kimura, M., Koike, H., Ueno, Y., et al. (2015). Vascularized and complex organ buds from diverse tissues via mesenchymal cell-driven condensation. Cell Stem Cell 16, 556-565. doi: 10.1016/j.stem.2015.03.004

Takebe, T., Sekine, K., Enomura, M., Koike, H., Kimura, M., Ogaeri, T., et al. (2013). Vascularized and functional human liver from an iPSC-derived organ bud transplant. Nature 499, 481-484. doi: 10.1038/nature12271

Thomson, J. A., Itskovitz-Eldor, J., Shapiro, S. S., Waknitz, M. A., Swiergiel, J. J., Marshall, V. S., et al. (1998). Embryonic stem cell lines derived from human blastocysts. Science 282, 1145-1147. doi: 10.1126/science.282.5391.1145
Tonello, C., Zavan, B., Cortivo, R., Brun, P., Panfilo, S., and Abatangelo, G. (2003). In vitro reconstruction of human dermal equivalent enriched with endothelial cells. Biomaterials 24, 1205-1211. doi: 10.1016/S0142-9612(02)00450-7

Townes, P. L., and Holtfreter, J. (1955). Directed movements and selective adhesion of embryonic amphibian cells. J. Exp. Zool. 128, 53-120. doi: 10.1002/jez.1401280105

Tufro, A., Norwood, V. F., Carey, R. M., and Gomez, R. A. (1999). Vascular endothelial growth factor induces nephrogenesis and vasculogenesis. J. Am. Soc. Nephrol. 10, 2125-2134.

Unbekandt, M., and Davies, J. A. (2010). Dissociation of embryonic kidneys followed by reaggregation allows the formation of renal tissues. Kid. Intern. 77, 407-416. doi: $10.1038 / \mathrm{ki} .2009 .482$

Usui, J.-I., Kobayashi, T., Yamaguchi, T., Knisely, A. S., Nishinakamura, R., and Nakauchi, H. (2012). Generation of kidney from pluripotent stem cells via blastocyst complementation. Am. J. Pathol. 180, 2417-2426. doi: 10.1016/j.ajpath.2012.03.007

Vigneau, C., Polgar, K., Striker, G., Elliott, J., Hyink, D., Weber, O., et al. (2007). Mouse embryonic stem cell-derived embryoid bodies generate progenitors that integrate long term into renal proximal tubules in vivo. J. Am. Soc. Nephrol.18, 1709-1720. doi: 10.1681/ASN.2006101078

Weiss, P., and Taylor, A. C. (1960). Reconstitution of complete organs from singlecell suspensions of chick embryos in advanced stages of differentiation. Proc. Natl. Acad. Sci. U.S.A. 46, 1177-1185. doi: 10.1073/pnas.46.9.1177

Wilm, B., James, R. G., Schultheiss, T. M., and Hogan, B. L. M. (2004). The forkhead genes, Foxc1 and Foxc2, regulate paraxial versus intermediate mesoderm cell fate. Dev. Biol. 271, 176-189. doi: 10.1016/j.ydbio.2004.03.034

Woolf, A. S., Gnudi, L., and Long, D. A. (2009). Roles of angiopoietins in kidney development and disease. J. Am. Soc. Nephrol. 20, 239-244. doi: 10.1681/ASN.2008020243

Xia, Y., Nivet, E., Sancho-Martinez, I., Gallegos, T., Suzuki, K., Okamura, D., et al. (2013). Directed differentiation of human pluripotent cells to ureteric bud kidney progenitor-like cells. Nat. Cell Biol. 15, 1507-1515. doi: 10.1038/ncb2872

Xia, Y., Sancho-Martinez, I., Nivet, E., Rodriguez Esteban, C., Campistol, J. M., and Izpisua Belmonte, J. C. (2014). The generation of kidney organoids by differentiation of human pluripotent cells to ureteric bud progenitor-like cells. Nat. Protoc. 9, 2693-2704. doi: 10.1038/nprot.2014.182

Xinaris, C., Benedetti, V., Rizzo, P., Abbate, M., Corna, D., Azzollini, N., et al. (2012). In vivo maturation of functional renal organoids formed from embryonic cell suspensions. J. Am. Soc. Nephrol. 23, 1857-1868. doi: 10.1681/ASN.2012050505

Yokoo, T., and Kawamura, T. (2009). Xenobiotic kidney organogenesis: a new avenue for renal transplantation. J. Nephrol. 22, 312-317.

Yokote, S., Matsunari, H., Iwai, S., Yamanaka, S., Uchikura, A., Fujimoto, E., et al. (2015). Urine excretion strategy for stem cell-generated embryonic kidneys. Proc. Natl. Acad. Sci. U.S.A. 112, 12980-12985. doi: 10.1073/pnas.150 7803112

Yokote, S., and Yokoo, T. (2013). Organogenesis for kidney regeneration. Curr. Opin. Organ Transplant. 18, 186-190. doi: 10.1097/MOT.0b013e328 $35 \mathrm{f} 070 \mathrm{~d}$

Conflict of Interest Statement: The authors declare that the research was conducted in the absence of any commercial or financial relationships that could be construed as a potential conflict of interest.

Copyright $\odot 2015$ Hariharan, Kurtz and Schmidt-Ott. This is an open-access article distributed under the terms of the Creative Commons Attribution License (CC BY). The use, distribution or reproduction in other forums is permitted, provided the original author(s) or licensor are credited and that the original publication in this journal is cited, in accordance with accepted academic practice. No use, distribution or reproduction is permitted which does not comply with these terms. 